\title{
Assessing the adequacy of essential nutrient intake in obese dogs undergoing energy restriction for weight loss: a cohort study
}

\author{
Alexander J. German ${ }^{1,2^{*}}$, Shelley L. Holden ${ }^{1,2}$, Samuel Serisier ${ }^{1,2}$, Yann Queau ${ }^{1,2}$ and Vincent Biourge ${ }^{1,2}$
}

\begin{abstract}
Background: Canine obesity is usually treated with dietary energy restriction, but data are limited regarding nutritional adequacy. The aim of the current study was to compare intake of essential nutrients with National Research Council recommendations in obese dogs during weight management with a purpose-formulated diet.

Methods: Twenty-seven dogs were included in this non-randomised retrospective observational cohort study. All were determined to be systemically well, and without significant abnormalities based upon physical examination and clinicopathological assessments. The dogs underwent a controlled weight loss protocol of at least 182 days' duration using a high protein high fibre weight loss diet. Median, maximum, and minimum daily intakes of all essential nutrients were compared against NRC 2006 recommended allowances (RA) for adult dogs.

Results: Median weight loss was $28 \%$ (16-40 \%), mean daily energy intake was $61 \mathrm{kcal} / \mathrm{kg}^{0.75}\left(44-74 \mathrm{kcal} / \mathrm{kg}^{0.75}\right)$, and no clinical signs of nutrient deficiency were observed in any dog. Based upon the average nutrient content of the diet, daily intake of the majority of essential nutrients was greater than their NRC 2006 recommended allowance (RA per kg body weight ${ }^{0.75}$ ), except for selenium, choline, methionine/cysteine, tryptophan, magnesium, and potassium. However, apart from choline (2/27 dogs) and methionine/cysteine (2/27 dogs), all essential nutrients remained above NRC minimum requirements (MR) throughout the trial.

Conclusions: When fed the diet used in the current study, daily intakes of most essential nutrients meet both their NRC 2006 RA and MR in obese dogs during weight loss. In light of absence of clinical signs of nutrient deficiency, it is unclear what significance intakes less that NRC cut-offs for some nutrients have (especially selenium and choline), and further studies are recommended.
\end{abstract}

Keywords: Canine, Caloric restriction, Nutritional adequacy

\section{Background}

Obesity is a common problem in dogs [1], and is associated with numerous diseases [1-3], metabolic derangements [4], alterations in renal function [5], respiratory dysfunction [6,7], decreased longevity [8], and decreased quality of life [9]. Management involves controlled weight loss by caloric restriction using a purpose-formulated weight loss diet [10-14]. Such diets are designed to ensure delivery of all essential nutrients appropriate to daily

\footnotetext{
* Correspondence: ajgerman@liverpool.ac.uk

'Department of Obesity and Endocrinology (Holden and German), University of Liverpool, Leahurst Campus, Chester High Road, Neston Wirral CH64 7TE, UK

${ }^{2}$ Royal Canin Research Center (Serisier, Queau, Biourge), 30470 Aimargues, France
}

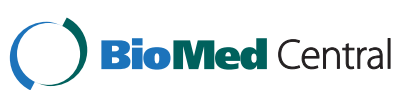

(c) 2015 German et al. Open Access This article is distributed under the terms of the Creative Commons Attribution 4.0 International License (http://creativecommons.org/licenses/by/4.0/), which permits unrestricted use, distribution, and reproduction in any medium, provided you give appropriate credit to the original author(s) and the source, provide a link to the Creative Commons license, and indicate if changes were made. The Creative Commons Public Domain Dedication waiver (http://creativecommons.org/publicdomain/zero/1.0/) applies to the data made available in this article, unless otherwise stated. requirements, despite sufficient energy restriction to prolight of the fact that the exact level of energy restriction required can vary considerably, with some dogs requiring marked caloric restriction [11, 12].

To ensure a diet is complete and balanced when fed at maintenance requirements, it is recommended that daily intake of all essential nutrients meet internationally accepted recommendations, such as those reported by National Research Council (NRC) [15], the Association of American Feed Control Officials (AAFCO) [16], and the European Pet Food Industry Federation (FEDIAF) [17]. It is currently assumed that dogs undergoing weight management continue to have similar 
essential nutrient requirements to those required for maintenance, although there is limited evidence to support this supposition. A recent study demonstrated that plasma concentrations of most essential nutrients do not change significantly during controlled weight loss using a purpose-formulated diet [18]. Furthermore, no clinically-evident nutrient deficiencies have previously been reported from a number of studies that have assessed the weight management process [10-14]. However, a recent theoretical study suggested the theoretical possibility that intake of some nutrients could be insufficient during the weight loss process, depending upon the diet used and the degree of energy restriction [19]. The main limitation of this study was the fact that all estimates of nutrient intake were theoretical, rather than being determined from the food intake of dogs actually undergoing weight management. As a result, the aim of the current study was to compare intake of essential nutrients with NRC recommendations in obese dogs during weight management with a purpose-formulated diet.

\section{Methods}

\section{Study design}

This was a non-randomised retrospective observational cohort study to assess intake of selected nutrients in a cohort of dogs with naturally occurring obesity, and has been reported according to the Strengthening and Reporting of Observational Studies in Epidemiology (STROBE) statement guidelines (Additional file 1) [20].

\section{Animals}

Participating dogs were recruited from referrals to the Royal Canin Weight Management Clinic, University of Liverpool UK, for management of obesity. The dogs were recruited between September 2006 and August 2010, and had completed weight loss by February 2011. To be eligible, all dogs had to be obese (based upon body fat measurement by dual-energy X-ray absorptiometry; DEXA) [11, 12], to have completed a weight loss regime (i.e. reaching target weight) of at least 182 days' duration (i.e. $\sim 6$ months duration), to have been fed the same purpose-formulated weight loss diet (Table 1; Royal Canin Satiety Canine Dry Diet, Royal Canin, UK), to be euthyroid (based upon measurement of serum free thyroxine concentration by equilibrium dialysis), and to have had no significant systemic disease (e.g. endocrine disease, hepatic disease, renal disease, and gastrointestinal disease) during the study. The study protocol adhered to the University of Liverpool Animal Ethics Guidelines, and was approved by both the University of Liverpool Research Ethics Committee and the Royal Canin Ethical Review Committee. Owners of all participating animals gave informed consent in writing.
Table 1 Average nutrient content of the diet used for weight loss in the study dogs

\begin{tabular}{|c|c|c|}
\hline \multirow{2}{*}{$\begin{array}{l}\text { Nutrient }^{a} \\
\text { Kcal/kg Metabolisable Energy }^{b}\end{array}$} & \multicolumn{2}{|l|}{ Weight loss diet } \\
\hline & 2900 & - \\
\hline & Per $100 \mathrm{~g}$ as fed & Per $1000 \mathrm{kcal}$ \\
\hline Crude protein (g) & 30 & 104.0 \\
\hline Arginine (g) & 1.6 & 5.4 \\
\hline Histidine (g) & 0.6 & 2.0 \\
\hline Isoleucine (g) & 1.1 & 3.8 \\
\hline Met and Cys (g) & 1.0 & 3.6 \\
\hline Leucine (g) & 2.2 & 7.7 \\
\hline Lysine (g) & 1.2 & 4.1 \\
\hline Phe and Tyr (g) & 2.8 & 9.6 \\
\hline Threonine (g) & 1.0 & 3.3 \\
\hline Tryptophan (g) & 0.3 & 0.9 \\
\hline Taurine $(g)^{c}$ & 0.2 & 0.7 \\
\hline Valine (g) & 1.3 & 4.4 \\
\hline Total fat (g) & 9.6 & 33.0 \\
\hline Linoleic acid (g) & 2.1 & 7.3 \\
\hline Calcium (g) & 0.9 & 3.1 \\
\hline Phosphorus (g) & 0.7 & 2.4 \\
\hline Magnesium (g) & 0.05 & 0.2 \\
\hline Sodium (g) & 0.3 & 1.0 \\
\hline Potassium (g) & 0.8 & 2.8 \\
\hline Chloride (g) & 0.9 & 3.0 \\
\hline Iron (mg) & 16.5 & 57.0 \\
\hline Copper (mg) & 2.0 & 6.9 \\
\hline Zinc (mg) & 20.0 & 69.0 \\
\hline Manganese (mg) & 7.0 & 24.0 \\
\hline Selenium (mg) & 0.02 & 0.1 \\
\hline lodine (mg) & 0.3 & 1.0 \\
\hline Vitamin A (IU) & 2027 & 6990 \\
\hline Vitamin D3 (IU) & 70 & 24 \\
\hline Vitamin $E(I U)$ & 80 & 276 \\
\hline Thiamine (mg) & 2.6 & 9.0 \\
\hline Riboflavin (mg) & 5.2 & 18.0 \\
\hline Pyridoxine (mg) & 2.3 & 8.0 \\
\hline Niacin (mg) & 16 & 56 \\
\hline Pantothenic acid (mg) & 4.6 & 16.0 \\
\hline Cobalamin (mg) & 0.02 & 0.06 \\
\hline Folic acid (mg) & 0.4 & 1.5 \\
\hline Choline (mg) & 249 & 860 \\
\hline
\end{tabular}

${ }^{a}$ The values reported are the average nutrient content as analysed bMetabolisable energy content, as measured in animal trials according to the AAFCO protocol [16]

'Although taurine is not an essential amino acid, it is supplemented within the diet 


\section{Weight loss regimen}

Full details of the weight loss regimen have been previously described $[11,12]$. Briefly, dogs were determined to be systemically well, and without significant abnormalities based upon physical examination and clinicopathological assessments (as detailed above). A controlled weight loss protocol was then initiated, using a high protein high fibre weight loss diet (Table 1). The initial food allocation for weight loss was determined by first estimating maintenance energy requirement $(\mathrm{MER}=440 \mathrm{~kJ}$ $[105 \mathrm{Kcal}] \times$ body weight $[\mathrm{kg}]^{0.75} /$ day $\left.[21]\right)$ using the estimated target weight. The exact level of restriction for each dog was then individualised based upon gender, and was typically between $50-60 \%$ of MER at target weight [11]. Owners also implemented lifestyle and activity alterations to assist in weight loss. Dogs were reweighed every 7-21 days and changes made to the food allocation if necessary.

Throughout weight loss, patients were weighed on electronic scales (Soehnle Professional, Backnang, Germany), which were regularly calibrated using test weights (Blake and Boughton Ltd, Thetford, UK). At the end of the weight management period, a detailed re-evaluation was conducted which included measurement of body weight, blood sampling, urinalysis, blood pressure measurement, and assessment of body composition assessed by fan-beam DEXA (Lunar Prodigy Advance; GE Lunar, Madison, Wisc, USA) [11, 22].

\section{Estimation of nutrient intake}

Average, maximum and minimum intakes of each nutrient were calculated for the period of weight management for each dog. Maximum and minimum daily intakes were defined as the greatest and least daily intake that the dog received during the period of controlled weight loss, whilst the average daily intake was defined as the mean daily intake for the whole weight loss period. The number (and percentage) of dogs with daily intake of essential nutrients less than NRC 2006 recommendations (per $\mathrm{kg}$ of ideal body weight ${ }^{0.75}$ ) was then determined, whereby minimum requirement (MR) was defined as 'the minimal concentration of a maximally bioavailable nutrient that will support a defined physiological state', recommended allowance (RA) was defined as 'the concentration of nutrient demonstrated to support a defined physiological state', and adequate intake (AI) was defined as 'the concentration of nutrient demonstrated to support a defined physiological state when no MR has been demonstrated' [15].

\section{Data handling and analysis}

All study data are available in the supplemental material (see Additional file 2). Absolute data are expressed as median (range). Datasets were complete for most variables except for four serum biochemistry variables where small numbers of results were missing: alkaline phosphatase (pre-weight-loss: 1 result), glucose (preweight-loss: 2 results; post-weight-loss: 3 results), phosphate (pre-weight-loss: 1 result), potassium (postweight-loss: 2 results), and free thyroxine (post-weightloss: 2 results). There were no other missing data for any variable. Given the small numbers of missing data points, no correction was made in statistical analysis. For each dog, the daily intake of all essential nutrients was calculated, based upon their food allocation and the average nutrient content of the diet (Table 1). Statistical analyses were performed with computer software (Stats Direct version 2.6.8, Stats Direct Ltd), with the level of significance set at $P<0.05$ for two-sided analyses. Given that there were no known previous studies examining adequacy of essential nutrient intake in obese dogs undergoing weight loss, it was not possible to perform a meaningful power calculation. Instead, as many dogs as possible were enrolled that the met the eligibility criteria. The Shapiro-Wilk test was used to assess all data sets and, because many were not normally distributed, non-parametric tests were used in preliminary analyses. These included the signed ranks test, the MannWhitney $U$ test, Kendall's rank correlation, and Fisher's exact test. In addition, simple and multiple regression analysis was used to determine associations between variables, and the Shapiro-Wilk test was also used to confirm that the distribution of the residuals of each regression model followed a normal distribution. Variables assessed included baseline variables (e.g. age, sex, neuter status, breed, and body fat percentage) and weight loss parameters (e.g. percentage weight loss, rate of weight loss, change in lean tissue, and energy intake during weight loss).

For linear regression of changes in lean tissue mass and circulating albumin concentration, factors tested included signalment (e.g. age at enrolment, sex, breed group [retriever vs. not retriever]), baseline parameters (e.g. percentage body fat pre-weight-loss, starting body weight, lean tissue mass pre-weight loss [in $\mathrm{kg}$ ]), weight loss outcomes (duration of weight loss, percentage weight loss, energy intake during weight loss, and percentage change in body fat mass), and nutrient status. For the latter, dogs were classified according to a binary variable, whereby $0=$ meets its NRC 2006 RA, and $1=$ does not meet its NRC 2006 RA. Both the average daily intake and the minimum daily intake during the weight loss period were assessed separately. Percentage change in fat mass was calculated using the following formula: (fat mass $[\mathrm{kg}]_{\text {POST }}$ - fat mass $\left.[\mathrm{kg}]_{\text {PRE }}\right) \div$ fat mass $\left.[\mathrm{kg}]_{\text {PRE }} \times 100\right)$; similarly, percentage change in lean mass was calculated as: (lean mass $[\mathrm{kg}]_{\text {POST }}-$ lean mass $\left.[\mathrm{kg}]_{\mathrm{PRE}}\right) \div$ lean mass $[\mathrm{kg}]_{\mathrm{PRE}} \times$ 
100). Initially, simple linear regression was used. A multiple linear regression model was then constructed, which initially included any variables identified as $P<0.2$ on univariable analysis. Collinearity amongst variables was assessed such that unnecessary collinear predictors were removed. The model was then refined by backwards-stepwise elimination of the least significant variable at each round, with variables being retained in the final model if they were significant $(P<0.05)$.

\section{Results}

\section{Dogs and outcome of weight loss}

During the study timeframe, a total of 149 dogs were enrolled in a weight loss regime and potentially eligible for study recruitment. Of these, 82 dogs reached their target weight, and the period of weight management was at least 182 days in 52 dogs. Of these 52 dogs, 40 had been fed a single type of dry food (Table 1). After excluding dogs that were not euthyroid, were not on concurrent medication, or had incomplete clinical data (laboratory and DEXA scan results), a final group of 27 dogs were eligible for inclusion. These dogs represented a range of ages, breeds and sexes (Table 2), and the median period of weight loss was 293 days (range 182-674 days). All dogs remained well throughout, and no dietrelated abnormalities were noted on physical examination, before, during, and after the period of weight loss. Median weight loss was $28.3 \%$ (16.0-40.1 \%) starting body weight (SBW), with a median rate of $0.6 \%$ (0.2-1.4\%) SBW/week, and the bulk of the tissue lost was fat with a lesser amount of lean tissue (Table 2). The mean daily energy intake during weight loss was $61 \mathrm{Kcal} / \mathrm{kg}^{0.75}\left(44-74 \mathrm{Kcal} / \mathrm{kg}^{0.75}\right)$, maximum daily energy intake was $63 \mathrm{Kcal} / \mathrm{kg}^{0.75}\left(45-77 \mathrm{Kcal} / \mathrm{kg}^{0.75}\right)$, and minimum daily energy intake was $60 \mathrm{Kcal} / \mathrm{kg}^{0.75}(43-71$ $\left.\mathrm{Kcal} / \mathrm{kg}^{0.75}\right)$.

\section{Laboratory assessments}

All dogs remained euthyroid throughout the trial, and serum free thyroxine concentration did not change significantly from beginning to end (Table $3 ; P=0.562$ ). Routine haematological and serum biochemical analyses were also performed (Table 3); occasional results were marginally outside the reference range, as reported in similar studies $[4,5,18]$. Also as previously reported $[4,5,18]$, white blood cell counts, and concentrations of albumin, calcium, cholesterol, creatinine, and globulins all decreased during weight loss, whilst urea concentration increased (Table 3). However, for the most part, changes were minor, and the majority remained within the reference range.
Table 2 Summary of weight loss in the study dogs

\begin{tabular}{|c|c|}
\hline Criterion & Result \\
\hline Age (months) & 70 (24 to 228$)$ \\
\hline Sex & $1 \mathrm{M}, 16 \mathrm{NM}, 1 \mathrm{~F}, 9 \mathrm{NF}$ \\
\hline Breed & $\begin{array}{l}\text { Alaskan Malamute, Border } \\
\text { Collie, CKCS (4), Cocker Spaniel, } \\
\text { Corgi, Dachshund, Doberman (2), } \\
\text { Golden Retriever, Irish Setter, } \\
\text { Labrador (6), Mixed Breed (3), } \\
\text { Pug (2), Samoyed, Yorkshire Terrier (2) }\end{array}$ \\
\hline Body weight PRE (kg) & $32.9(6.7$ to 66.8$)$ \\
\hline Body weight POST (kg) & $23.2(5.0$ to 48.0$)$ \\
\hline Body fat mass PRE (\%) & 47 (31 to 55$)$ \\
\hline Body fat mass POST (\%) & 30 (19 to 45$)$ \\
\hline Duration (days) & 293 (182 to 674) \\
\hline Rate of weight loss (\%/week) & $0.6(0.2$ to 1.4$)$ \\
\hline Body weight change $(\%)^{b}$ & $-28.3(-16.0$ to -40.1$)$ \\
\hline Change in fat mass $(\%)^{b}$ & $-52(-67$ to -16$)$ \\
\hline Change in lean mass $(\%)^{b}$ & $-10(-21$ to +5$)$ \\
\hline El during weight loss ${ }^{c}$ & 256 (184 to 308 ) [61 (44 to 74$)]$ \\
\hline
\end{tabular}

All data are expressed as median (range). M: male; NM: neutered male; F: female; NF: neutered female; CKCS: Cavalier King Charles Spaniel ${ }^{a}$ Rate of weight loss expressed as percentage of starting body weight lost per week

${ }^{b}$ Refers to the percentage change in starting mass calculated as follows: ([start mass - end mass] $\div$ start mass) $\times 100 \%$

'El: energy intake expressed as metabolisable energy (in $\mathrm{kJ}$ [Kcal]) per kg of metabolic body weight $\left(\mathrm{BW}^{0.75}\right)$ per day

\section{Comparison with National Research Council 2006 recommendations}

Average, maximum and minimum daily intakes of essential nutrients for each dog (expressed per $\mathrm{kg} \mathrm{BW}^{0.75}$ ) were calculated for the whole weight management period (Table 4), and compared with NRC 2006 recommendations (Table 5). The intake of the majority of essential nutrients was greater than all NRC 2006 cut-offs, with the exception of selenium, choline, methionine and cysteine, tryptophan, total fat, magnesium, and potassium. For selenium, the minimum daily intake was less than both RA and AI in all dogs. For choline, the minimum daily intake was less than RA in $24 / 27$ dogs (89\%), but less than AI in only 2 dogs $(7 \%)$. For methionine and cysteine, the minimum daily intake was less than RA in 12 dogs (44\%), but minimum intake was never less than MR in only 2 dogs $(7 \%)$. Finally, minimum daily intake was less than RA for tryptophan (2 dogs, $7 \%$ ), magnesium (27 dogs, $100 \%$ ), and potassium ( 2 dogs, 7 \%), but was never less than MR in any dog.

\section{Association between nutrients with borderline intakes and changes in either lean tissue and serum albumin concentration}

Given that, in some dogs, intake of certain nutrients was borderline, the possibility that these might be associated 
Table 3 Haematological and clinical biochemical results before and after weight loss

\begin{tabular}{|c|c|c|c|c|}
\hline Parameter & Before weight loss & After weight loss & Reference range & $P$ value \\
\hline Red blood cells $\times 10^{12} / \mathrm{L}$ & $6.9(5.3-8.1), 0,2$ & $6.9(5.3-8.0), 0,1$ & $5.5-8.2$ & 0.652 \\
\hline Haemoglobin $\mathrm{g} / \mathrm{L}$ & $16.0(12.4-18.8), 0,2$ & $16.0(11.3-17.9), 0,3$ & $12.6-19.4$ & 0.690 \\
\hline Haematocrit L/L & $0.48(0.36-0.55), 0,0$ & $0.47(0.35-0.54), 0,0$ & $0.35-0.55$ & 0.880 \\
\hline Platelets $\times 10^{9} / \mathrm{L}$ & $276(13-385), 0,2$ & $266(140-444), 0,0$ & $80-560$ & 0.473 \\
\hline White blood cells $\times 10^{9} / \mathrm{L}$ & $10.4(5.1-18.7), 2,1$ & $8.2(4.6-14.0), 0,5$ & $6.7-18.3$ & $<0.001$ \\
\hline Sodium $\mathrm{mmol} / \mathrm{L}$ & $147(142-153), 0,0$ & $146(140-151), 0,0$ & $140-153$ & 0.155 \\
\hline Potassium mmol/L & $4.6(3.8-6.0), 1,0$ & $4.2(3.7-6.0), 1,1$ & $3.8-5.3$ & 0.199 \\
\hline Calcium $\mathrm{mmol} / \mathrm{L}$ & $2.8(2.3-3.1), 3,0$ & $2.6(1.8-2.9), 0,2$ & $2.20-2.90$ & $<0.001$ \\
\hline Phosphate $\mathrm{mmol} / \mathrm{L}$ & $1.0(0.5-2.2), 1,3$ & $1.0(0.5-1.5), 0,5$ & $0.8-2.0$ & 0.058 \\
\hline Alanine aminotransferase $U / L$ & $44(18-293), 13,0$ & 49 (18-238), 13, 0 & $7-50$ & 0.893 \\
\hline Alkaline phosphatase U/L & $74(23-392), 11,0$ & 54 (26-295), 8, 0 & $0-100$ & 0.065 \\
\hline Albumin $\mathrm{g} / \mathrm{L}$ & $32(28-36), 1,0$ & $29(25-36), 2,0$ & $25-35$ & $<0.001$ \\
\hline Cholesterol $\mathrm{mmol} / \mathrm{L}$ & $6.1(4.1-7.9), 5,0$ & $5.4(3.0-7.3), 1,2$ & $3.5-7.0$ & 0.040 \\
\hline Creatinine $\mu \mathrm{mol} / \mathrm{L}$ & $84(44-123), 2,0$ & $72(46-114), 1,0$ & 20-110 & 0.033 \\
\hline Globulins $\mathrm{g} / \mathrm{L}$ & $31(22-44), 2,0$ & $27(23-42), 1,0$ & $22-40$ & 0.012 \\
\hline Glucose $\mathrm{mmol} / \mathrm{L}$ & $5.1(3.3-5.9), 5,1$ & $5.2(3.0-7.4), 5,1$ & $3.5-5.5$ & 0.210 \\
\hline Urea mmol/L & $4.6(1.8-7.6), 4,5$ & $5.2(2.4-8.9), 1,1$ & $3.5-7.0$ & 0.047 \\
\hline Free thyroxine $\mathrm{pmol} / \mathrm{L}$ & $21.0(7.0-42.9), 2,0$ & 20.0 (8.4-34.0), 0, 0 & $6.6-40.0$ & 0.562 \\
\hline
\end{tabular}

with changes in lean tissue mass and circulating albumin concentration was explored using linear regression. Selenium was not assessed separately because all dogs had intakes less than RA and, therefore, this factor did not discriminate dogs. On simple linear regression analysis (Table 6), one factor (percentage weight loss) was significantly associated with change in lean tissue during weight loss $\left(R=-0.55, R^{2}=0.30, P=0.003\right)$, whilst a number of other factors were also eligible for inclusion in the preliminary multiple linear regression model $(P<$ $0.2)$ including: age $\left(R=-0.27, R^{2}=0.07, P=0.170\right)$, rate of weight loss $\left(R=-0.33, R^{2}=0.11, P=0.092\right)$, energy intake $\left(R=0.28, R^{2}=0.08, P=0.152\right)$, average daily intake of methionine and cysteine $\left(R=-0.32, R^{2}=0.10, P=0.107\right)$, and minimum daily intake of choline mean $\left(R=-0.31, R^{2}=\right.$ $0.10, P=0.111)$. After refinement of the initial model by backwards stepwise elimination, the best-fit model was one that included a single variable, percentage weight loss (more lean tissue loss when greater percentage weight loss; $R=-0.55, R^{2}=0.31, P=0.003$; Table 6). Thus, essential nutrient intake was not associated with changes in lean tissue during weight loss.

Simple linear regression analysis revealed that only the duration of weight loss was significantly associated with changes in serum albumin concentration $\left(R=-0.39, R^{2}=\right.$ $0.15, P=0.046)$. Two other factors also qualified for inclusion in the preliminary multiple regression model: body fat prior to weight loss $\left(R=-0.28, R^{2}=0.08, P=0.150\right)$, and the minimum daily intake of choline during weight loss $\left(R=0.26, R^{2}=0.07, P=0.184\right)$. Once again, after refinement by backwards stepwise elimination, the best-fit model was one that included the single variable, duration of weight loss (the longer the weight loss period, the greater the decrease in albumin; $R=-0.39$, $R^{2}=0.15, P=0.046$; Table 7). Thus, essential nutrient intake was not associated with changes in albumin concentration during weight loss.

\section{Discussion}

In the current study, we have assessed the intake of essential nutrients for obese dogs during a period of controlled weight loss using a purpose-formulated diet. The intake of most essential nutrients exceeded NRC 2006 RA cut-offs. Although intake was less than RA or MR for some nutrients, all dogs remained healthy, showing no clinical signs of nutrient deficiency. It is important to note that RAs include a safety margin to take into account predicted nutrient bioavailability, and the actual bioavailability of individual nutrients might be higher than assumed in NRC 2006. The significance of dogs having intakes less than MR for some nutrients during weight loss is not known. Firstly, it is possible that requirements for essential nutrients might actually change when dogs are subjected to energy restriction, although 
Table 4 Daily intake of essential nutrients in 27 obese dogs during weight loss

\begin{tabular}{|c|c|c|c|}
\hline \multirow[t]{2}{*}{ Nutrient } & \multicolumn{3}{|l|}{ Daily intake } \\
\hline & $\overline{\text { Maximum }^{a}}$ & Minimum $^{\mathrm{b}}$ & Average $^{c}$ \\
\hline Crude protein (g) & $6.55(4.70-8.04)$ & $6.23(4.46-7.38)$ & $6.35(4.58-7.64)$ \\
\hline Arginine (g) & $0.342(0.245-0.419)$ & $0.324(0.232-0385)$ & $0.331(0.239-0.398)$ \\
\hline Histidine (g) & $0.129(0.092-0.158)$ & $0.122(0.087-0.145)$ & $0.125(0.090-0.150)$ \\
\hline Isoleucine (g) & $0.237(0.170-0.291)$ & $0.225(0.161-0.267)$ & $0.230(0.166-0.276)$ \\
\hline Methionine \& cysteine (g) & $0.22(0.16-0.28)$ & $0.21(0.15-0.25)$ & $0.22(0.16-0.26)$ \\
\hline Leucine (g) & $0.49(0.35-0.60)$ & $0.46(0.33-0.55)$ & $0.47(0.34-0.57)$ \\
\hline Lysine (g) & $0.259(0.186-0.318)$ & $0.246(0.176-0.292)$ & $0.251(0.181-0.302)$ \\
\hline Phenylalanine \& tyrosine (g) & $0.61(0.44-0.74)$ & $0.58(0.41-0.68)$ & $0.59(0.42-0.71)$ \\
\hline Threonine (g) & $0.21(0.15-0.26)$ & $0.20(0.14-0.23)$ & $0.20(0.15-0.24)$ \\
\hline Tryptophan (g) & $0.059(0.042-0.072)$ & $0.056(0.040-0.066)$ & $0.057(0.041-0.068)$ \\
\hline Valine $(g)$ & $0.27(0.20-0.34)$ & $0.26(0.19-0.31)$ & $0.27(0.19-0.32)$ \\
\hline Linoleic acid (g) & $0.46(0.33-0.56)$ & $0.43(0.31-0.51)$ & $0.44(0.32-0.53)$ \\
\hline Calcium (g) & $0.195(0.140-0.240)$ & $0.186(0.133-0.220)$ & $0.189(0.136-0.228)$ \\
\hline Phosphorus (g) & $0.15(0.11-0.19)$ & $0.14(0.10-0.17)$ & $0.15(0.11-0.18)$ \\
\hline Magnesium (mg) & $10.7(7.7-13.1)$ & $10.2(7.3-12.1)$ & $10.4(7.5-12.5)$ \\
\hline Sodium (mg) & $63.0(45.2-77.3)$ & $59.9(42.8-71.0)$ & $61.0(44.0-73.5)$ \\
\hline Potassium (g) & $0.18(0.13-0.22)$ & $0.17(0.12-0.20)$ & $0.17(0.12-0.21)$ \\
\hline Chloride (mg) & $189(136-232)$ & $180(129-213)$ & $183(132-221)$ \\
\hline Iron (mg) & $3.6(2.6-4.4)$ & $3.4(2.4-4.0)$ & $3.5(2.5-4.2)$ \\
\hline Copper (mg) & $0.4(0.3-0.5)$ & $0.4(0.3-0.5)$ & $0.4(0.3-0.5)$ \\
\hline Zinc (mg) & $4.3(3.1-5.3)$ & $4.1(3.0-4.9)$ & $4.2(3.0-5.1)$ \\
\hline Manganese (mg) & $1.5(1.1-1.9)$ & $1.4(1.0-1.7)$ & $1.5(1.1-1.8)$ \\
\hline Selenium $(\mu g)$ & $5.1(3.7-6.1)$ & $5.2(3.8-6.4)$ & $5.0(3.6-5.9)$ \\
\hline lodine (mg) & $63.0(45.2-77.3)$ & $59.9(42.8-71.0)$ & $61.0(44.0-73.5)$ \\
\hline Vitamin A (IU) & $440(316-541)$ & $418(299-496)$ & $427(308-514)$ \\
\hline Vitamin D3 (IU) & $15.25(10.94-18.71)$ & $14.49(10.37-17.18)$ & $14.77(10.65-17.79)$ \\
\hline Vitamin E (IU) & $17.4(12.5-21.3)$ & 16.5 (11.8-19.6) & $16.8(12.2-20.3)$ \\
\hline Thiamine (mg) & $0.567(0.407-0.696)$ & $0.539(0.386-0.639)$ & $0.549(0.396-0.662)$ \\
\hline Riboflavin (mg) & $1.134(0.814-1.392)$ & $1.078(0.771-1.278)$ & $1.099(0.792-1.323)$ \\
\hline Pyridoxine (mg) & $0.504(0.362-0.619)$ & $0.479(0.343-0.568)$ & $0.488(0.352-0.588)$ \\
\hline Niacin (mg) & $3.53(2.53-4.33)$ & $3.35(2.40-3.97)$ & $3.42(2.47-4.12)$ \\
\hline Pantothenic acid (mg) & $1.01(0.72-1.24)$ & $0.96(0.69-1.14)$ & $0.98(0.70-1.18)$ \\
\hline Cobalamin $(\mu g)$ & $3.47(2.49-4.25)$ & $3.29(2.36-3.90)$ & $3.36(2.42-4.04)$ \\
\hline Folic acid $(\mu g)$ & $94.5(67.8-116.0)$ & 89.8 (64.3-106.5) & $91.6(66.0-110.3)$ \\
\hline Choline (mg) & $54.2(38.9-66.5)$ & $51.5(36.8-61.0)$ & $52.5(37.9-63.2)$ \\
\hline
\end{tabular}

The daily intake of all essential nutrients was calculated from their food allocation and the average nutrient content of the diet (Table 1 ), and expressed per kg $\mathrm{BW}^{0.75}$. Results are quoted as median (range)

${ }^{a}$ Maximum daily intake defined as the greatest daily intake that the dog received during the period of controlled weight loss

${ }^{\mathrm{b}}$ Minimum daily intakes defined as the least daily intake that the dog received during the period of controlled weight loss

${ }^{c}$ Mean daily intake was defined as the mean daily intake for the whole period

the exact effect may well differ amongst nutrients. For example, requirements of many amino acids and B vitamins are directly related to energy metabolism $[15,23]$. Given that MER declines during weight loss [13], the requirement of some essential nutrients might also decline. In contrast, requirements for other essential nutrients (i.e. minerals) are more directly related to bodyweight, or another exponent, rather than to energy metabolism [15]. For these essential nutrients, requirements might not change during weight loss despite the 
Table 5 Obese dogs not meeting NRC requirements during weight loss

\begin{tabular}{|c|c|c|c|c|c|c|c|c|c|}
\hline \multirow[t]{2}{*}{ Nutrient } & \multicolumn{3}{|c|}{ Recommended allowance $^{a}$} & \multicolumn{3}{|c|}{ Adequate intake $^{b}$} & \multicolumn{3}{|c|}{ Minimum requirement ${ }^{c}$} \\
\hline & $\overline{N R C^{d}}$ & No. less ${ }^{e}$ & $\%^{f}$ & $\overline{N R C}$ & No. less ${ }^{e}$ & $\%^{f}$ & $N R C$ & No. less ${ }^{\mathrm{e}}$ & $\%^{f}$ \\
\hline Crude protein (g) & 3.28 & $0,0,0$ & $0,0,0$ & - & - & - & 2.62 & $0,0,0$ & $0,0,0$ \\
\hline Arginine (g) & 0.110 & $0,0,0$ & $0,0,0$ & - & - & - & 0.092 & $0,0,0$ & $0,0,0$ \\
\hline Histidine (g) & 0.062 & $0,0,0$ & $0,0,0$ & - & - & - & 0.048 & $0,0,0$ & $0,0,0$ \\
\hline Isoleucine (g) & 0.120 & $0,0,0$ & $0,0,0$ & - & - & - & 0.098 & $0,0,0$ & $0,0,0$ \\
\hline Methionine \& cysteine (g) & 0.21 & $7,12,9$ & $26,44,33$ & - & - & - & 0.17 & $1,2,1$ & $4,7,4$ \\
\hline Leucine $(g)$ & 0.22 & $0,0,0$ & $0,0,0$ & - & - & - & 0.18 & $0,0,0$ & $0,0,0$ \\
\hline Lysine (g) & 0.110 & $0,0,0$ & $0,0,0$ & - & - & - & 0.092 & $0,0,0$ & $0,0,0$ \\
\hline Phenylalanine \& tyrosine (g) & 0.24 & $0,0,0$ & $0,0,0$ & - & - & - & 0.19 & $0,0,0$ & $0,0,0$ \\
\hline Threonine (g) & 0.14 & $0,0,0$ & $0,0,0$ & - & - & - & 0.11 & $0,0,0$ & $0,0,0$ \\
\hline Tryptophan (g) & 0.046 & $1,2,1$ & $4,7,4$ & - & - & - & 0.036 & $0,0,0$ & $0,0,0$ \\
\hline Valine (g) & 0.16 & $0,0,0$ & $0,0,0$ & - & - & - & 0.13 & $0,0,0$ & $0,0,0$ \\
\hline Linoleic acid (g) & 0.36 & $0,0,0$ & $0,0,0$ & 0.30 & $0,0,0$ & $0,0,0$ & - & - & - \\
\hline Calcium (g) & 0.130 & $0,0,0$ & $0,0,0$ & - & - & - & 0.059 & $0,0,0$ & $0,0,0$ \\
\hline Phosphorus (g) & 0.10 & $0,0,0$ & $0,0,0$ & 0.10 & $0,0,0$ & $0,0,0$ & - & - & - \\
\hline Magnesium (mg) & 19.70 & $27,27,27$ & $100,100,100$ & - & - & - & 5.91 & $0,0,0$ & $0,0,0$ \\
\hline Sodium (mg) & 26.2 & $0,0,0$ & $0,0,0$ & - & - & - & 9.85 & $0,0,0$ & $0,0,0$ \\
\hline Potassium (g) & 0.14 & $1,2,1$ & $4,7,4$ & 0.14 & $1,2,1$ & $4,7,4$ & - & - & - \\
\hline Chloride (mg) & 40 & $0,0,0$ & $0,0,0$ & 40 & $0,0,0$ & $0,0,0$ & - & - & - \\
\hline Iron (mg) & 1.0 & $0,0,0$ & $0,0,0$ & 1.0 & $0,0,0$ & $0,0,0$ & - & - & - \\
\hline Copper (mg) & 0.2 & $0,0,0$ & $0,0,0$ & 0.2 & $0,0,0$ & $0,0,0$ & - & - & - \\
\hline Zinc (mg) & 2.0 & $0,0,0$ & $0,0,0$ & 2.0 & $0,0,0$ & $0,0,0$ & - & - & - \\
\hline Manganese (mg) & 0.16 & $0,0,0$ & $0,0,0$ & 0.16 & $0,0,0$ & $0,0,0$ & - & - & - \\
\hline Selenium $(\mu g)$ & 11.8 & $27,27,27$ & $100,100,100$ & 11.8 & $27,27,27$ & $100,100,100$ & - & - & - \\
\hline lodine (mg) & 29.6 & $0,0,0$ & $0,0,0$ & - & - & - & 23.6 & $0,0,0$ & $0,0,0$ \\
\hline Vitamin A (IU) & 50 & $0,0,0$ & $0,0,0$ & 40 & $0,0,0$ & $0,0,0$ & - & - & - \\
\hline Vitamin D3 (IU) & 0.45 & $0,0,0$ & $0,0,0$ & 0.36 & $0,0,0$ & $0,0,0$ & - & - & - \\
\hline Vitamin E (IU) & 1.0 & $0,0,0$ & $0,0,0$ & 0.8 & $0,0,0$ & $0,0,0$ & - & - & - \\
\hline Thiamine (mg) & 0.074 & $0,0,0$ & $0,0,0$ & 0.059 & $0,0,0$ & $0,0,0$ & - & - & - \\
\hline Riboflavin (mg) & 0.171 & $0,0,0$ & $0,0,0$ & - & - & - & 0.138 & $0,0,0$ & $0,0,0$ \\
\hline Pyridoxine (mg) & 0.049 & $0,0,0$ & $0,0,0$ & - & - & - & 0.040 & $0,0,0$ & $0,0,0$ \\
\hline Niacin (mg) & 0.49 & $0,0,0$ & $0,0,0$ & 0.39 & $0,0,0$ & $0,0,0$ & - & - & - \\
\hline Pantothenic acid (mg) & 0.49 & $0,0,0$ & $0,0,0$ & 0.40 & $0,0,0$ & $0,0,0$ & - & - & - \\
\hline Cobalamin $(\mu g)$ & 1.15 & $0,0,0$ & $0,0,0$ & 0.92 & $0,0,0$ & $0,0,0$ & - & - & - \\
\hline Folic acid $(\mu g)$ & 8.9 & $0,0,0$ & $0,0,0$ & 7.1 & $0,0,0$ & $0,0,0$ & - & - & - \\
\hline Choline (mg) & 56.0 & $17,24,20$ & $63,89,74$ & 45.0 & $1,2,1$ & $4,7,4$ & - & - & - \\
\hline
\end{tabular}

${ }^{a}$ Recommended allowance: the concentration of nutrient demonstrated to support a defined physiological state [15]

${ }^{\mathrm{b}}$ Adequate intake: the concentration of nutrient demonstrated to support a defined physiological state when no minimal requirement has been demonstrated [15]

${ }^{c}$ Minimum requirement: the minimal concentration of a maximally bioavailable nutrient that will support a defined physiological state [15]

${ }^{\mathrm{d}}$ All requirements are expressed as the unit stated per $\mathrm{kg} \mathrm{BW}^{0.75}$

eThe number of dogs with nutrient intakes less than NRC cut-off based upon maximum, minimum, and mean daily intakes, respectively

${ }^{T}$ The percentage of dogs with nutrient intakes less than NRC cut-off based upon maximum, minimum, and mean daily intakes, respectively. Please see the footnote of Table 4 for definitions of maximum, minimum and mean intakes

decrease in MER. A second issue is the fact that for loss of lean tissue mass to be minimised during weight loss, intake of dietary protein must be adequate [14]. However, it is not known which essential amino acids are most limiting in a purpose-formulated weight management diet. Therefore, additional studies are now required to assess adequate intake of essential nutrients during weight loss. 
Table 6 Simple and multiple linear regression analysis to determine factors associated with change in lean mass

\begin{tabular}{|c|c|c|c|}
\hline Variable & $\mathrm{R}$ & $\mathrm{R}^{2}$ & Probability \\
\hline \multicolumn{4}{|l|}{ Simple regression } \\
\hline $\mathrm{Age}^{\mathrm{a}}$ & -0.27 & 0.07 & 0.170 \\
\hline Sex & 0.09 & 0.01 & 0.658 \\
\hline Neuter status & -0.14 & 0.02 & 0.471 \\
\hline Duration of weight loss & 0.057 & 0.00 & 0.781 \\
\hline Percentage weight loss & -0.55 & 0.30 & 0.003 \\
\hline Mean El during weight loss ${ }^{b}$ & 0.28 & 0.08 & 0.152 \\
\hline Mean rate of weight loss ${ }^{c}$ & -0.33 & 0.11 & 0.092 \\
\hline Starting percentage body fat & -0.28 & 0.08 & 0.152 \\
\hline Change in fat mass ${ }^{d}$ & 0.11 & 0.01 & 0.605 \\
\hline \multicolumn{4}{|l|}{ Mean daily intake $<\mathrm{RDA}^{\mathrm{e}}$} \\
\hline Methionine \& Cysteine & -0.32 & 0.10 & 0.107 \\
\hline Tryptophan & -0.21 & 0.05 & 0.282 \\
\hline Choline & -0.13 & 0.02 & 0.514 \\
\hline \multicolumn{4}{|l|}{ Minimum daily intake $<\mathrm{RDA}^{f}$} \\
\hline Methionine \& Cysteine & -0.21 & 0.05 & 0.282 \\
\hline Tryptophan & 0.05 & 0.00 & 0.790 \\
\hline Choline & -0.31 & 0.10 & 0.111 \\
\hline \multicolumn{4}{|l|}{ Final multiple regression model } \\
\hline Percentage weight loss & -0.55 & 0.30 & 0.003 \\
\hline
\end{tabular}

All data are expressed as median (range). El: energy intake; RDA: recommended daily allowance

${ }^{a}$ Age at the start of the weight loss programme

${ }^{\mathrm{b}}$ Mean energy intake expressed as metabolisable energy (in $\mathrm{kJ}$ [Kcal]) per kg of metabolic body weight $\left(\mathrm{BW}^{0.75}\right)$ per day

${ }^{\mathrm{c}}$ Mean rate of weight loss expressed as percentage of starting body weight per week

${ }^{\mathrm{d}}$ Percentage change in fat mass between the start and end of the weight loss period

${ }^{e}$ Dummy variable created whereby $1=$ the mean daily intake of each nutrient less than the NRC 2006 RA, and 0 when it was greater [15]

fDummy variable created whereby 1 was assigned when the minimum daily intake of the nutrient less than the NRC 2006 RA, and 0 was assigned when it was greater [15]

The majority of essential nutrients were fed at intakes (per $\mathrm{kg} \mathrm{BW}^{0.75} /$ day) above the guidelines recommended by NRC, throughout the weight loss period. However, there were some important exceptions to this, most notably selenium, choline, methionine and cysteine. At first glance, results were most concerning for selenium, since daily intakes for this mineral were less than AI in all cases. Selenium is involved in antioxidant pathways as well as both thyroid and immune system function, with deficiency reportedly causing anorexia, depression, dyspnoea, and coma [24]. None of these signs were evident in any of the dogs of the current study. Excessive dietary selenium intake can also have adverse effects in dogs [24]; further, both AAFCO and FEDIAF have set legal limits for selenium supplementation. Thus, it can be immensely challenging to formulate a diet appropriately for
Table 7 Simple and multiple linear regression analysis to determine factors associated with change in serum albumin concentration

\begin{tabular}{|c|c|c|c|}
\hline Variable & $\mathrm{R}$ & $R^{2}$ & Probability \\
\hline \multicolumn{4}{|l|}{ Simple regression } \\
\hline $\mathrm{Age}^{\mathrm{a}}$ & 0.22 & 0.05 & 0.274 \\
\hline Sex & 0.18 & 0.03 & 0.357 \\
\hline Neuter status & 0.01 & 0.00 & 0.956 \\
\hline Duration of weight loss & -0.39 & 0.15 & 0.046 \\
\hline Percentage weight loss & 0.01 & 0.00 & 0.941 \\
\hline Mean El during weight loss ${ }^{b}$ & 0.04 & 0.00 & 0.856 \\
\hline Mean rate of weight loss ${ }^{c}$ & 0.19 & 0.04 & 0.344 \\
\hline Starting percentage body fat & -0.28 & 0.08 & 0.150 \\
\hline Change in fat mass ${ }^{d}$ & -0.02 & 0.00 & 0.921 \\
\hline Change in lean mass $^{d}$ & -0.07 & 0.00 & 0.718 \\
\hline \multicolumn{4}{|l|}{ Mean daily intake $<\mathrm{RDA}^{\mathrm{e}}$} \\
\hline Methionine \& Cysteine & -0.12 & 0.01 & 0.566 \\
\hline Tryptophan & -0.03 & 0.00 & 0.895 \\
\hline Choline & -0.07 & 0.00 & 0.714 \\
\hline \multicolumn{4}{|l|}{ Minimum daily intake $<\operatorname{RDA}^{f}$} \\
\hline Methionine \& Cysteine & -0.14 & 0.02 & 0.482 \\
\hline Tryptophan & -0.03 & 0.00 & 0.894 \\
\hline Choline & 0.26 & 0.07 & 0.184 \\
\hline \multicolumn{4}{|l|}{ Final multiple regression model } \\
\hline Duration of weight loss & -0.39 & 0.15 & 0.046 \\
\hline
\end{tabular}

All data are expressed as median (range). El: energy intake; RDA: recommended daily allowance

${ }^{\mathrm{a} A g e}$ at the start of the weight loss programme

${ }^{\mathrm{b}}$ Mean energy intake expressed as metabolisable energy (in $\mathrm{kJ}$ [Kcal]) per kg of metabolic body weight $\left(\mathrm{BW}^{0.75}\right)$ per day

${ }^{c} M e a n$ rate of weight loss expressed as percentage of starting body weight per week

${ }^{d}$ Percentage change in fat or lean mass between the start and end of the weight loss period; positive and negative values represent gains and losses in lean mass, respectively

${ }^{e}$ Dummy variable created whereby $1=$ the mean daily intake of each nutrient less than the NRC 2006 RA, and 0 when it was greater [15]

fDummy variable created whereby 1 was assigned when the minimum daily intake of the nutrient less than the NRC 2006 RA, and 0 was assigned when it was greater [15]

selenium content. A second challenge with selenium is the fact that optimal intake is not as easily determined as for other nutrients. Most notably, NRC does not report MR for selenium in dogs and, to the authors' knowledge, no studies have examined this, partly because it can be difficult to measure selenium status accurately in animals. Nonetheless, a recent in vivo study in obese dogs, that used the same diet as for the current work, did not reveal any decrease in selenium status during weight loss. In fact, urinary selenium excretion was greater after weight loss, compared with before, perhaps suggesting that requirements for this essential nutrient might actually decline during weight loss [18]. 
Therefore, although less than NRC AI, the intake of selenium in all dogs was probably sufficient.

Choline is a vitamin-like substance that is reportedly involved in neurotransmission, hepatic lipid metabolism, coagulation, as well as acting as a methyl donor [15]. In dogs, deficiency of choline causes hypocholesterolaemia, vomiting, fatty liver disease, and death [25]. A previous theoretical study suggested that intake of choline might be at risk of deficiency if marked caloric restriction was required during weight loss [19]. In the current study, the daily choline intake of most dogs (24/27, 89 \%) was less than the NRC 2006 RA for some of their period of weight loss, although intake was less than the suggested AI in only two dogs (7 \%). However, requirements for choline have not been well established in dogs, and the current $\mathrm{AI}$ for choline is based on data from studies conducted over 50 years ago [16]. Therefore, it is unclear as to whether daily choline intake during the current study was actually deficient. That said, a recent study, that used the same diet as for the current work, demonstrated a $16 \%$ decrease in plasma choline concentrations during weight loss in obese dogs [18]. Given that choline is a relatively easy nutrient to supplement and there are minimal toxicity concerns, increasing the choline content of canine weight management diets would seem be sensible until more data on choline requirements are available.

Similar to the issues for choline, the intake of methionine and cysteine were less than RA in $12(44 \%)$ and less than MR in 2 (7\%) of the dogs undergoing weight loss in the current study. As with choline, these amino acids were also identified as 'at risk' in a recent theoretical study [19]. Methionine is a sulphur-containing amino acid that is not only required for protein synthesis, but also forms part of the coenzyme s-adenosyl methionine [26]. As a result, its deficiency can result in various metabolic aberrations [26]. Cysteine is a critical amino acid for maintaining the secondary structure of compounds such as glutathione and those required for hair synthesis. Cysteine is synthesised from methionine and, therefore, both amino acids are typically considered together when determining requirements. When methionine is deficient in the diet, there is an immediate decrease in food intake, and severe weight loss [27]. Whilst all dogs lost weight during the study, this was not likely to be due to methionine or cysteine deficiency because food intake was never affected and weight loss occurred in a controlled fashion and was never excessive (i.e. $<3 \%$ per week). Puppies fed a methionine-deficient diet also develop dermatological lesions such as erythema, footpad necrosis and hyperkeratosis [28], while adult dogs fed a diet with borderline methionine and taurine content, develop gallstones $[29,30]$. None of the dogs in the current study, or indeed from the larger cohort of dogs seen at our weight management clinic, developed any dermatological signs at any stage during or after their period of weight loss. Given that abdominal ultrasonography was not performed, it is unclear as to whether or not gallstones had developed. That said, this possibility is less likely, given that the diet was also supplemented with taurine (which can partially substitute for methionine and cysteine), and none of the dogs were taurine deficient (data not shown). Further, no signs were noted pertaining to liver disease, and clinicopathological markers of biliary system disturbance (e.g. bilirubin, and liver enzyme activity) were unchanged after weight loss. Finally, given the requirement of both methionine and cysteine for protein synthesis, the effect of daily intake on change in lean tissue mass and also serum albumin concentration were assessed, and no associations were seen with either. Nonetheless, as with choline, supplementing methionine and cysteine in the current diet by $15 \%$ would ensure that daily intake is greater than NRC MR. Such a reformulation would be sensible until further data are available clarifying the safety of intakes of the level in the current study.

There were a number of other nutrients where intake was less than the RA suggested by the NRC [15]. These included tryptophan, magnesium, and potassium. The significance of these observations is not known since intake was always above MR throughout weight loss, there were no signs of deficiency for any of these nutrients, and no association was seen with changes in lean tissue or serum albumin.

As with all studies, a number of limitations exist. Firstly, the data were collected retrospectively, and dogs included were drawn from a larger population. Given the eligibility criteria used, and most notably the duration of the weight loss period, a number of dogs were excluded since they reached target weight within 6 months. Other dogs were excluded because different weight loss diets had been used, clinical data were missing, the dogs either had another disease, or they were on concurrent drug therapy. It is possible that, by excluding dogs in this way, the results might have been unfairly biased. That said, dogs were not excluded for becoming sick or ill, perhaps the most important outcome factor of interest for the study. Further, to the authors' knowledge, no nutrient deficiencies have ever been recognised in any dog that has attended the weight management clinic where the study was conducted, and this includes the dogs from the current study. Nonetheless, it would be worth considering a prospective study, to confirm the current findings in a cohort of obese dogs undergoing weight loss.

Given that client-owned dogs were used, a second limitation was the diversity in the population of dogs 
used, which is arguably more marked than would have been the case for a study undertaken on dogs from a research colony. Not only was the population more diverse, but also the environment in which the dogs were kept was more variable, not least with regard to controlling food intake. To offset this, owners measured food out precisely using kitchen scales, maintained a diary record, and dogs were only included dogs if there was no evidence of poor compliance i.e. recorded feeding of additional foodstuffs. That said, under-reporting is a concern with the use of food questionnaires [11, 31] and, as a result, it is possible that some dogs received additional food, causing errors in estimation of adequate intake. Whilst this is a notable limitation, the use of client-owned dogs means that the results are arguably more representative for the target population of interest, than using dogs from a research colony.

A third limitation regarding the population was the fact that it was very variable in terms of breed, age gender, presence of concurrent diseases, and in outcome. For this reason we applied very strict eligibility criteria, for instance measurement of body composition by DEXA. As a result, the final population was closely monitored, well phenotyped, and all data were complete.

A fourth limitation was the fact that, since the study was conducted over a number of years and there was no actual analysis of the batches of food used. Instead, the nutrient intake for each dog was based upon the average nutrient content of the diet, based upon analysis. Thus, actual nutrient intake might have differed from that reported in the current study. Further, whilst we observed no obvious clinical signs of malnutrition, based upon physical examination, the outcomes measured might not have adequately assessed nutrient status or detected subclinical deficiencies. For instance, plasma nutrient status was not measured. However, such a study has recently been performed, in a similar cohort of dogs [18], which demonstrated no change in the plasma concentrations of most key nutrients during weight loss.

A final limitation relates to generalisability of the data to canine weight loss programmes in general. Given the use of client-owned dogs, results should be broadly representative of weight loss programmes using this or similar diets in practice although, since the final population was small, subtle individual issues with a particular breed or dog type might have been missed. Further, the population came from a referral clinic and so might not be typical of the usual dogs undergoing weight management. Moreover, only a single weight loss diet was used and, thus, findings might not be generalisable to other weight loss diets, especially those from other manufacturers. Therefore, it would be worth considering individual validation of other weight loss strategies in the future.

\section{Conclusion}

In conclusion, the current study reports daily intakes of essential nutrients in a cohort of obese dogs that successfully completed a weight loss regime of at least 6 months' duration, and showed no signs of nutrient deficiency. For some essential nutrients, such as selenium, choline, methionine and cysteine, daily intake was borderline in some dogs during weight loss.

\section{Additional files}

Additional file 1: STROBE 2007 (v4 Statement-Checklist of items that should be included in reports of cohort studies. (PDF $89 \mathrm{~kb}$ )

Additional file 2: Study data. (XLSX 254 kb)

\section{Abbreviations}

AAFCO: Association of american feed control officials; Al: Adequate intake; BCS: Body condition score; BW: Body weight; DEXA: Dual-energy X-ray absorptiometry; DM: Dry matter; FEDIAF: European pet food industry federation; HCT: Haematocrit; LC-MS/MS: Liquid chromatography-tandem mass spectrometry; MR: Minimum requirement; NRC: National research council; RA: Recommended allowance.

\section{Competing interests}

AJG's Readership is funded by Royal Canin; AJG has also received financial remuneration and gifts for providing educational material, speaking at conferences, and consultancy work; SLH's post at the University of Liverpool is also funded by Royal Canin; the diet used in this study is manufactured by Royal Canin; SS, YQ and VB are employed by Royal Canin.

\section{Authors' contributions}

AJG: designed the study, collected the clinical data, analysed the results, drafted the manuscript; SLH: collected clinical data, and reviewed manuscript; SS: contributed to discussions on study design, discussed clinical data, reviewed the manuscript; YQ: contributed to discussions on study design, checked nutrient data, reviewed the manuscript; VB: designed the study, discussed clinical data, checked nutrient data, reviewed the manuscript. All authors have approved the final article.

\section{Acknowledgements}

The study was funded by a grant from Mars Petcare (VCR10030). The authors wish to acknowledge the referring veterinarians for referring cases, the owners of all dogs for allowing them to participate, and the clinical staff at the University of Liverpool for assistance with case management.

Received: 10 August 2015 Accepted: 30 September 2015 Published online: 07 October 2015

\section{References}

1. German AJ. The growing problem of obesity in dogs and cats. J Nutr. 2006;136:1940S-6S

2. Hess RS, Kass PH, Shofer FS, Van Winkle TJ, Washabau RJ. Evaluation of risk factors for fatal acute pancreatitis in dogs. J Amer Vet Med Assoc. 1999;214:46-51.

3. Lund EM, Armstrong PJ, Kirk CA, Klausner JS. Prevalence and risk factors for obesity in adult dogs from private US veterinary practices. Int J Appl Res Vet Med. 2006;4:177-86.

4. German AJ, Hervera M, Hunter L, Holden SL, Morris PJ, Biourge V, et al. Improvement in insulin resistance and reduction in plasma inflammatory adipokines after weight loss in obese dogs. Domest Anim Endocrinol. 2009;37:214-26.

5. Tvarijonaviciute A, Ceron JJ, Holden SL, Morris PJ, Biourge V, German AJ. Effect of Weight Loss in Obese Dogs on Indicators of Renal Function or Disease. J Vet Intern Med. 2013;27:31-8.

6. Bach JF, Rozanski EA, Bedenice D, Bach JF, Rozanski EA, Bedenice D, et al Association of expiratory airway dysfunction with marked obesity in healthy adult dogs. Am J Vet Res. 2007;68:670-5. 
7. Mosing M, German AJ, Holden SL, MacFarlane P, Biourge V, Morris PJ, et al. Oxygenation and ventilation characteristics in obese sedated dogs before and after weight loss: A clinical trial. Vet J. 2013;198:367-71.

8. Kealy RD, Lawler DF, Ballam JM, Mantz SL, Biery DN, Greeley EH. Effects of diet restriction on life span and age-related changes in dogs. J Am Vet Med Assoc. 2002;220:1315-20.

9. German AJ, Holden SL, Wiseman-Orr ML, Reid J, Nolan AM, Biourge V, et al. Quality of life is reduced in obese dogs but improves after successful weight loss. Vet J. 2012;192:428-34.

10. Blanchard G, Nguyen P, Gayet C, Leriche I, Siliart B, Paragon BM. Rapid weight loss with a high-protein low energy diet allows the recovery of ideal body composition and insulin sensitivity in obese dogs. J Nutr. 2004; 134:2148S-50S

11. German AJ, Holden SL, Bissot T, Hackett RM, Biourge V. Dietary energy restriction and successful weight loss in obese client-owned dogs. J Vet Intern Med. 2007;21:1174-80.

12. German AJ, Holden SL, Bissot T, Morris PJ, Biourge V. A high-protein high-fibre diet improves weight loss in obese dogs. Vet J. 2010;183:294-7.

13. German AJ, Holden SL, Mather NJ, Morris PJ, Biourge V. Low maintenance energy requirements of obese dogs after weight loss. Brit J Nutr. 2011;106:S93-6.

14. Diez M, Nguyen P, Jeusette I, Devois C, Istasse L, Biourge V. Weight loss in obese dogs: evaluation of a high-protein, low-carbohydrate diet. J Nutr. 2002;132:1685S-7S

15. Ad Hoc Committee on Dog and Cat Nutrition, National Research Council. Nutrient requirements and dietary concentrations. In: Nutrient Requirements of Dogs and Cats. Washington DC: National Academies Press; 2006. p. 354-0.

16. Association of American Food control officials (AAFCO). Official Publication. West Lafayette: AAFCO; 2014.

17. The European Pet Food Industry Federation (FEDIAF). Nutritional guidelines for complete and complementary pet food for dogs and cats. 2015. http://www.fediaf.org/self-regulation/nutrition/. Accessed 24 September 2015.

18. Linder DE, Freeman LM, Holden SL, Biourge V. German AJ Status of selected nutrients in obese dogs undergoing caloric restriction. BMC Vet Res. 2013:9:219.

19. Linder DE, Freeman LM, Morris P, German AJ, Biourge V, Heinze C, et al. Theoretical evaluation of risk for nutritional deficiency with caloric restriction in dogs. Vet Quart. 2012;32:123-9.

20. Von Elm E, Altman DG, Egger M, Pocock SJ, Gotzsche PC, Vandenbroucke $J P$. The strengthening the reporting of observational studies in epidemiology (Additional file 1: STROBE) statement: guidelines for reporting observational studies. Bull World Health Organ. 2007;85:867-72.

21. Ad Hoc Committee on Dog and Cat Nutrition, National Research Council. Energy. In: Nutrient Requirements of Dogs and Cats. Washington DC: National Academies Press; 2006. p. 22-48.

22. Raffan E, Holden SL, Cullingham F, Hackett R, Rawlings J, German AJ. Standardised positioning is essential for precise determination of body composition using dual-energy X-ray absorptiometry. J Nutr. 2006;136:1976S-8S.

23. Shils ME, Shike M, Ross AC, Cabalerro B, Cousins RJ. Modern Nutrition in health and disease. 10th ed. Philadelphia: Lippincott: Williams \& Wilkins; 2006.

24. Ad Hoc Committee on Dog and Cat Nutrition, National Research Council. Minerals. In: Nutrient Requirements of Dogs and Cats. Washington DC: National Academies Press; 2006. p. 145-92.

25. Fascetti AJ, Delaney SJ. Essential nutrient deficiency signs and clinically available or relevant methods of assessing nutrient status. In: Fascetti AJ, Delaney SJ, editors. Applied Veterinary Clinical Nutrition. Edited by. Chichester: Wiley-Blackwell; 2012. p.14-20. https://books.google.co.uk/ books?id=elyL9qss6qsC\&pg=PA14\&lpg=PA14\&dq=Essential+nutrient +deficiency+signs+and+clinically+available+or+relevant+methods+of +assessing+nutrient+status\&source=bl\&ots=y4ldaEyy $T$ Tsig=oBZ86PYgaB9R_rXmuiSb5OVipU\&hl=en\&sa=X\&ved=0CCcQ6AEwAWoVChMIuD_nKyryAIVxzkUCh0OawA8\#v=onepage\&q=Essential\%20nutrient $\%$ 20deficiency\%20signs\%20and\%20clinically\%20available\%20or\%20 relevant $\% 20$ methods $\% 20$ of $\% 20$ assessing $\% 20$ nutrient $\% 20$ status $\& f=f a l s e$

26. Brosnan JT, Brosnan ME. The sulfur-containing amino acids: an overview. J Nutr. 2006;136:1636S-40S.

27. Rose WC, Rice EE. The significance of amino acids in canine nutrition. Science. 1939;30:186-7.
28. Hirakawa DA, Baker DH. Sulfur amino acid nutrition in the growing puppy: determination of dietary requirements for methionine and cystine. Nutr Res. 1985;5:631-42.

29. Dawes LG, Nahrwold DL, Roth SI, Rege RV. Reversal of pigment gallstone disease in a canine model. Arch Surg. 1989;124:463-6.

30. Christian JS, Rege RV. Methionine, but not taurine, protects against formation of canine pigment gallstones. J Surg Res. 1996;61:275-81.

31. Heitmann BL, Lissner L, Osler M. Do we eat less fat, or just report so? Int J Obesity. 2000;24:435-42.

\section{Submit your next manuscript to BioMed Central and take full advantage of:}

- Convenient online submission

- Thorough peer review

- No space constraints or color figure charges

- Immediate publication on acceptance

- Inclusion in PubMed, CAS, Scopus and Google Scholar

- Research which is freely available for redistribution 